\title{
Risk-Factor Analysis of Disc and Facet Joint Degeneration After Inter-Segmental Pedicle Screw Fixation for Lumbar Spondylolysis
}

Hao Meng ( $\nabla$ menghaospine@163.com )

the 7th Medical Center of PLA General Hospital

\section{Yuan Gao}

the 1st Medical Center of PLA General Hospital

\section{Peng Lu}

the 7th Medical Center of PLA General Hospital

\section{Guang-Min Zhao}

the 7th Medical Center of PLA General Hospital

\section{Zhi-Cheng Zhang}

the 7th Medical Center of PLA General Hospital

Tian-Sheng Sun

the 7th Medical Center of PLA General Hospital

\section{Fang Li}

the 7th Medical Center of PLA General Hospital

\section{Research article}

Keywords: spondylolysis, pedicle screw fixation, risk factors, disc degeneration, facet joint degeneration

Posted Date: September 16th, 2021

DOI: https://doi.org/10.21203/rs.3.rs-880039/v1

License: @ (i) This work is licensed under a Creative Commons Attribution 4.0 International License. Read Full License 


\section{Abstract}

Background: To assess the effects of inter-segment pedicle screw fixation for the treatment of lumbar spondylolysis, and evaluate various risk factors potentially predicting the probability of disc and facet joint degeneration after instrumentation.

Methods: The study included 54 male L5 spondylolysis patients who underwent pars repair and intersegment fixation using pedicle screws. Bony union was evaluated using reconstruction images of computed tomography. Radiographic changes including the disc height, vertebral slip, facet joint and disc degeneration in the grade of adjacent and fixed segments were determined from before to final follow-up. Logistic regression analysis was performed to identify factors associated with the incidence of disc and facet joint degeneration.

Results: Bony union was achieved in all cases. Logistic regression analysis revealed that duration of instrumentation of more than 15.5 months and 21.0 months were significant risk factor of the incidence of L4/5 and L5S1 facet degeneration, respectively.

Conclusions: Inter-segmental pedicle screw fixation provides good surgical outcomes and good isthmic bony union rates in patients with lumbar spondylolysis. The duration of fixation was confirmed as a risk factor of facet joint degeneration. Once bony union is achieved, remove of the instruments should be recommended.

\section{Background}

Lumbar spondylolysis refers to a defect of the vertebral pars interarticularis caused by stress fracture and occurs in approximately $6 \%$ of the general population, the incidence of symptomatic spondylolysis is reported to be higher in athletes(1). The lesion is mainly located at L5 (71-95\%), L4 (5-23\%) but can occur at any level $(2,3)$.

Generally, patients with low back pain because of spondylolysis are often managed conservatively with medication, physical therapy, and injection treatment $(4,5)$. Surgery is indicated when failure of a comprehensive conservative treatment for more than 6 months, persistent back pain and pars non-union. Increasing pain, worsening of preexisted neurological impairment and progressive olisthesis are also indications for surgical treatment $(4,6,7)$.

In this study, we use direct repair plus inter-segment pedicle screw fixation for the treatment of lumbar spondylolysis. Although this method has fixed one active segment and may limit spinal flexibility and causes loads between segments adjacent to the fixed segments, resulting in the problem of adjacent segment degeneration (ASD) $(8,9)$, pedicle screws can be removed when bony-union was achieved, and whether degeneration in adjacent segments are accelerated is still unclear. To our knowledge, postoperative instability between adjacent segments, facet joint and disc degeneration have not been examined in a single-center study of cases in which lumbar inter-segmental pedicle screw fixation was performed. 
The purposes of this study were to reveal the effects of inter-segment pedicle screw fixation for the treatment of lumbar spondylolysis, and evaluate various risk factors potentially predicting the probability of disc and facet joint degeneration.

\section{Materials And Methods}

\section{Patients}

We retrospectively evaluated consecutive spondylolysis patients who underwent pars repair and segmental fixation using pedicle screws at our institution between January 2016 and January 2018. All 54 patients were male and the lesion is located at L5. Patients with symptomatic spondylolysis were treated with direct iliac bone graft repair combined with inter-segmental pedicle screw fixation. Plain radiographs, computed tomography (CT) and magnetic resonance imaging (MRI) were evaluated at six, twelve, 18 and 24 months postoperatively. Instrumentation was removed after bony union was achieved (illustrative case, Fig. 1).

Spondylolysis of the lumbar spine was diagnosed as follows: all patients with low back pain had taken simple radiographs of the lumbar spine (anteroposterior, lateral, and oblique views), and if needed, CT scan was taken to confirm the presence or absence of spondylolysis. In addition, the patients with definite spondylosis on the lumbar spine radiographs and CT scans underwent MRI of the lumbar spine to detect

other spinal problems, such as disc degeneration and herniation. Surgery was indicated when patients with low back pain for a diagnosis of lumbar spondylolysis, did not respond to conservative treatments for at least 6 months, and no disc or slight degeneration at the level of pars defect were found in the MRI scans. Exclusion criteria were radiological signs of spondylolisthesis or instability, previous spinal surgery, significant radicular pain, and who had improved following conservative treatment.

\section{Operative Procedures}

A posterior midline incision was made. After incision of lumbosacral fascia at $2 \mathrm{~cm}$ paraspinous process, the mutifidus and longissimus muscles were identified and dissected away. The pars defects were exposed, carefully leaving facet joints intact. The lysis was prepared by removing fibrous tissue in and around the gap. The bony elements on both sides of the lysis were decorticated to assure bony healing of the lysis after pars repair. Cancellous bone grafts were taken from the posterior iliac crest and implanted into the pars. Four pedicle screws were implanted to fix the isthmic vertebral and the adjacent distal vertebral. Instrumentation was removed after bony fusion was achieved.

\section{Radiological outcomes}

Bony union was evaluated using reconstruction images of CT at each follow-up. Reconstructions were made in both the axial and the sagittal planes, allowing to determine a degree of union.

Radiographic changes including the disc height, vertebral slip, facet joint and disc degeneration in the grade of adjacent and fixed segments were determined from pre-operation to final follow-up. Relationships between CT and MRI findings and the progression of degeneration based on preoperative grade were also evaluated. 
Disc height and vertebral slip at the L4/5 and L5/S1 levels were measured on lateral plain radiographs. The disc height was measured by Miyakoshi's procedures(10). On a lateral radiograph, the following points to be marked were identified: the corners of the vertebral bodies, the midpoints of the endplates, and the midpoints of the walls of the vertebral bodies; the points were determined strictly according to the criteria of Quint et al.(11). Using these easily defined points, the height of the L4/5 and L5S1 discs were measured. The disc height $(\mathrm{DH})$ was calculated as the mean of the anterior, middle, and posterior disc heights. The sagittal diameter of the vertebral body from the anterior to posterior margin was measured at the midvertebral level, disc height index (DHI) was calculated as disc height/ sagittal diameter of the vertebral $\operatorname{body}(12)$.

Disc degeneration of the adjacent and fixed segments were reviewed using MRI during the follow-up. Disc degenerative grading was measured using the Pfirrmann 5-grade classification, which includes grades 1 to 5(13). Facet joint degeneration was measured using the classification for osteoarthritis of the Japanese Orthpaedic Association (JOA), which includes grades 0 to 4. Grade 0 indicates severe degeneration and Grade 4 indicates a normal joint without degeneration(14).

All surgeries were performed using same procedures at our institution, the incidence of complications was compared between the two groups. Potential risk factors of disc and facet joint degeneration, such as age, obesity (Body Mass Index, BMI), duration of the fixation, vertebral slip, and facet joint degeneration before primary surgery, were identified by reviewing medical records. Imaging assessment was assessed by 2 spine surgeons (ZCZ and GMZ)

The Student $t$ test or analysis of variance was used for continuous variables and the Fisher exact test for categorical variables. SPSS software, version 23.0 (SPSS, Chicago, IL, USA) was used for all analyses, and a two-sided $p$ value $<0.05$ was considered statistically significant. Logistic regression analysis was performed to identify factors independently associated with the incidence of disc and facet joint degeneration.

\section{Results}

At the time of the primary surgery, the mean age was 22.76 years (18 to 34). Mean BMI was $22.81 \mathrm{~kg} / \mathrm{m}^{2}$ (19.23 to 24.77). Bony union was achieved in all cases, as confirmed by CT reconstruction, the mean fixed time was 17.04 months (8 to 39 ). No complications were observed during the follow-up.

Cases of disc and facet joint degeneration detected on plain radiographs are shown in Table 1. Decreased disc height in the upper adjacent segment $L 4 / 5$ of $\geq 20 \%$ occurred in one patient, whereas decreased disc height in the fixed segment L5/S1 of $\geq 20 \%$ was observed in one patient. Decreased disc height in the upper adjacent segment $L 4 / 5$ between $20 \%$ and $10 \%$ occurred in 7 patients, whereas in the fixed segment L5/S1 was observed in 8 patients. CT indicated facet joint degeneration at L4/5 and L5/S1 in 7 and 9 patients, respectively. MRI showed disc degeneration at L4/5 and L5/S1 in 5 and 5 patients, respectively. 
Table 1

Radiographic disc and facet joint degeneration.

\begin{tabular}{|lll|}
\hline & L4/5 (\%) & L5S1 (\%) \\
\hline X-ray & & \\
\hline DH: decrease $\geq 20 \%$ & $1(2 \%)$ & $1(2 \%)$ \\
\hline DH: $20 \% \geq$ decrease $\geq 10 \%$ & $7(13 \%)$ & $8(15 \%)$ \\
\hline CT & & \\
\hline Facet degeneration +1 grade & $7(13 \%)$ & $7(13 \%)$ \\
\hline Facet degeneration $>1$ grade & 0 & $2(4 \%)$ \\
\hline MRI & & \\
\hline Disc degeneration +1 grade & $5(9 \%)$ & $5(9 \%)$ \\
\hline Disc degeneration $>1$ grade & 0 & 0 \\
\hline DH: disc height. & & \\
\hline
\end{tabular}

The mean disc height in the upper adjacent segment $L 4 / 5$ was $14.17 \pm 1.74$ before surgery, and $14.01 \pm$ 2.23 after removal of instruments. The mean $\mathrm{DHI}$ in the $L 4 / 5$ was $0.381 \pm 0.03$ before surgery, and $0.370 \pm$ 0.04 after removal of instruments. The mean disc height in the fixed segment L5/S1 was $14.13 \pm 1.90$ before surgery, and $13.82 \pm 2.03$ after removal of instruments. The mean DHI in the L5S1 was $0.389 \pm 0.05$ before surgery, and $0.380 \pm 0.05$ after removal of internal fixation, no significant difference was observed (Table 2). There were 15 patients with $\mathrm{DHI}$ decrease $\geq 10 \%, 39$ patients with $\mathrm{DHI}$ decrease $\leq 10 \%$. For the L5S1level, the number of patients with pre-operative facet joint degeneration were 9 patients in DHI decrease $\geq 10 \%$, and 34 patients in DHI decrease $<10 \%$. The difference was significant $(p<0.05)$. The number of patients with pre-operative disc degeneration were 12 patients in DHI decrease $\geq 10 \%$, and 29 patients in DHI decrease $<10 \%$, however, the difference was not significant $(p>0.05)$ (Table 3 ). For the L $4 / 5$ level, no significant differences were observed between the DHI changes and pre-operative facet joint and disc degeneration (Table 3).

Table 2

Radiographic changes of disc height on plain radiographs.

\begin{tabular}{|lcccc|}
\hline & Pre-operation & Post-operation & t value & P value \\
\hline DH (L4/5) & $14.17 \pm 1.74$ & $14.01 \pm 2.23$ & 0.760 & 0.451 \\
\hline DHI (L4/5) & $0.381 \pm 0.03$ & $0.370 \pm 0.04$ & 1.993 & 0.051 \\
\hline DH (L5S1) & $14.13 \pm 1.90$ & $13.82 \pm 2.03$ & 1.712 & 0.093 \\
\hline DHI (L5S1) & $0.389 \pm 0.05$ & $0.380 \pm 0.05$ & 1.772 & 0.082 \\
\hline DH: disc height; DHI: disc height index. & & \\
\hline
\end{tabular}


Table 3

Relationship between pre-operative disc and facet joint status and disc degeneration.

\begin{tabular}{|c|c|c|c|c|c|c|c|c|}
\hline & \multicolumn{4}{|l|}{ L4/5 } & \multicolumn{4}{|l|}{ L5S1 } \\
\hline & $\begin{array}{l}\text { DHI } \\
\text { decrease } \\
\geq 10 \% \\
\text { (n) }\end{array}$ & $\begin{array}{l}\text { DHI } \\
\text { decrease } \\
<10 \%(n)\end{array}$ & $\begin{array}{l}F \\
\text { value }\end{array}$ & $\begin{array}{l}P \\
\text { value }\end{array}$ & $\begin{array}{l}\mathrm{DHI} \\
\text { decrease } \\
\geq 10 \% \\
\text { (n) }\end{array}$ & $\begin{array}{l}\text { DHI } \\
\text { decrease } \\
<10 \% \text { (n) }\end{array}$ & $\begin{array}{l}F \\
\text { value }\end{array}$ & $\begin{array}{l}P \\
\text { value }\end{array}$ \\
\hline $\begin{array}{l}\text { Facet grade } \\
\text { pre-operation }\end{array}$ & & & 0.000 & 1.000 & & & 4.934 & $0.026^{*}$ \\
\hline $\begin{array}{l}\text { Degeneration } \\
\geq 1 \text { grade }\end{array}$ & 8 & 32 & & & 9 & 34 & & \\
\hline $\begin{array}{l}\text { No } \\
\text { degeneration }\end{array}$ & 3 & 11 & & & 6 & 5 & & \\
\hline $\begin{array}{l}\text { Disc grade } \\
\text { pre-operation }\end{array}$ & & & $0.002^{*}$ & 0.964 & & & 0.006 & 0.937 \\
\hline $\begin{array}{l}\text { Degeneration } \\
\geq 1 \text { grade }\end{array}$ & 8 & 34 & & & 12 & 29 & & \\
\hline $\begin{array}{l}\text { No } \\
\text { degeneration }\end{array}$ & 3 & 9 & & & 3 & 10 & & \\
\hline \multicolumn{9}{|c|}{ DH: disc height; DHI: disc height index. } \\
\hline
\end{tabular}

In the analysis of L4/5 and L5S1 disc degeneration, there were no significant differences in demographic data (age, BMI, duration of instrument fixation, vertebral slip, and preoperative facet and disc degeneration change) (Table 4). In the analysis of L4/5 facet degeneration, there were no significant differences in demographic data (BMI, vertebral slip, and preoperative facet and disc degeneration change), however, facet degeneration group showed a significantly older age and longer duration of instrument fixation than no degeneration group (Table 5). In the analysis of L5S1 facet degeneration, there were no significant differences in demographic data (age, vertebral slip, and preoperative facet and disc degeneration change), facet degeneration group showed a significantly higher BMI and longer duration of instrument fixation than no degeneration group (Table 5). 
Table 4

The analysis of risk factors for L4/5 and L5S1 discs.

\begin{tabular}{|c|c|c|c|c|c|c|c|c|}
\hline & \multicolumn{3}{|l|}{ L4/5 } & \multicolumn{2}{|c|}{ L5S1 } & \multirow[b]{2}{*}{$\begin{array}{l}\text { No } \\
\text { change }\end{array}$} & & \multirow[b]{2}{*}{$\begin{array}{l}P \\
\text { value }\end{array}$} \\
\hline & Degeneration & $\begin{array}{l}\text { No } \\
\text { change }\end{array}$ & & $\begin{array}{l}P \\
\text { value }\end{array}$ & Degeneration & & & \\
\hline Age (y) & $25.60 \pm 5.46$ & $\begin{array}{l}22.47 \\
\pm 4.42\end{array}$ & 1.479 & 0.145 & $23.00 \pm 5.15$ & $\begin{array}{l}22.73 \\
\pm 4.55\end{array}$ & 0.123 & 0.903 \\
\hline BMI & $22.34 \pm 1.97$ & $\begin{array}{l}22.86 \\
\pm 0.91\end{array}$ & -1.070 & 0.290 & $22.69 \pm 0.51$ & $\begin{array}{l}22.82 \\
\pm 1.08\end{array}$ & -0.257 & 0.799 \\
\hline $\begin{array}{l}\text { Fixed } \\
\text { time }(\mathrm{m})\end{array}$ & $17.60 \pm 1.97$ & $\begin{array}{l}16.98 \\
\pm 6.51\end{array}$ & 0.202 & 0.841 & $15.20 \pm 4.97$ & $\begin{array}{l}17.29 \\
\pm 6.61\end{array}$ & -0.684 & 0.497 \\
\hline $\begin{array}{l}\text { Vertebral } \\
\text { slip (n) }\end{array}$ & 5 & 49 & 0.117 & 0.732 & 5 & 49 & $0.000 *$ & 1.000 \\
\hline yes & 1 & 19 & & & 2 & 18 & & \\
\hline no & 4 & 30 & & & 3 & 31 & & \\
\hline $\begin{array}{l}\text { Facet } \\
\text { grade pre- } \\
\text { operation }\end{array}$ & 5 & 49 & 2.305 & 0.310 & & & 1.870 & 0.641 \\
\hline Grade 4 & 0 & 13 & & & 4 & 7 & & \\
\hline Grade 3 & 5 & 28 & & & 7 & 14 & & \\
\hline Grade 2 & 0 & 8 & & & 4 & 9 & & \\
\hline Grade 1 & 0 & 0 & & & 1 & 8 & & \\
\hline Grade 0 & 0 & 0 & & & 0 & 0 & & \\
\hline $\begin{array}{l}\text { Disc } \\
\text { grade pre- } \\
\text { operation }\end{array}$ & 5 & 49 & 3.094 & 0.347 & 5 & 49 & 6.854 & 0.113 \\
\hline Grade 1 & 2 & 9 & & & 3 & 10 & & \\
\hline Grade 2 & 2 & 26 & & & 0 & 22 & & \\
\hline Grade 3 & 0 & 10 & & & 2 & 10 & & \\
\hline Grade 4 & 1 & 4 & & & 0 & 6 & & \\
\hline Grade 5 & 0 & 0 & & & 0 & 1 & & \\
\hline
\end{tabular}

BMI: Body Mass Index.

* Test was considered statistically significant at $P<0.05$. 
Table 5

The analysis of risk factors for L4/5 and L5S1 facet joints.

\begin{tabular}{|c|c|c|c|c|c|c|c|c|}
\hline & L4/5 & & & & L5S1 & & & \\
\hline & Degeneration & $\begin{array}{l}\text { No } \\
\text { change }\end{array}$ & & $\begin{array}{l}P \\
\text { value }\end{array}$ & Degeneration & $\begin{array}{l}\text { No } \\
\text { change }\end{array}$ & & $\begin{array}{l}P \\
\text { value }\end{array}$ \\
\hline Age (y) & $26.29 \pm 5.38$ & $\begin{array}{l}22.23 \\
\pm 4.24\end{array}$ & 2.278 & $0.027^{\star}$ & $23.22 \pm 4.82$ & $\begin{array}{l}22.67 \\
\pm 4.56\end{array}$ & 0.331 & 0.742 \\
\hline BMI & $23.37 \pm 0.59$ & $\begin{array}{l}22.72 \\
\pm 1.06\end{array}$ & 1.572 & 0.122 & $23.49 \pm 0.81$ & $\begin{array}{l}22.67 \\
\pm 1.03\end{array}$ & 2.225 & $0.030 *$ \\
\hline $\begin{array}{l}\text { Fixed } \\
\text { time }(m)\end{array}$ & $25.86 \pm 8.86$ & $\begin{array}{l}15.72 \\
\pm 4.98\end{array}$ & 4.495 & $0.000 *$ & $25.56 \pm 4.67$ & $\begin{array}{l}15.33 \\
\pm 5.39\end{array}$ & 5.297 & $0.000 *$ \\
\hline $\begin{array}{l}\text { Vertebral } \\
\text { slip (no.) }\end{array}$ & & & 0.000 & 1.000 & & & 1.922 & 0.166 \\
\hline yes & 3 & 17 & & & 1 & 19 & & \\
\hline no & 4 & 30 & & & 8 & 26 & & \\
\hline $\begin{array}{l}\text { Facet } \\
\text { grade } \\
\text { pre- } \\
\text { operation }\end{array}$ & & & 0.614 & 0.852 & & & 3.569 & 0.389 \\
\hline Grade 4 & 1 & 13 & & & 1 & 10 & & \\
\hline Grade 3 & 5 & 27 & & & 4 & 17 & & \\
\hline Grade 2 & 1 & 7 & & & 3 & 10 & & \\
\hline Grade 1 & 0 & 0 & & & 1 & 8 & & \\
\hline Grade 0 & 0 & 0 & & & 0 & 0 & & \\
\hline $\begin{array}{l}\text { Disc } \\
\text { grade } \\
\text { pre- } \\
\text { operation }\end{array}$ & & & 2.934 & 0.317 & & & 6.404 & 0.145 \\
\hline Grade 1 & 1 & 11 & & & 1 & 12 & & \\
\hline Grade 2 & 2 & 26 & & & 6 & 16 & & \\
\hline Grade 3 & 2 & 7 & & & 0 & 12 & & \\
\hline Grade 4 & 2 & 7 & & & 2 & 4 & & \\
\hline Grade 5 & 0 & 0 & & & 0 & 1 & & \\
\hline \multicolumn{9}{|c|}{ BMI: Body Mass Index. } \\
\hline * Test was & nsidered stati & cally siqr & cant at & $<0.05$ & & & & \\
\hline
\end{tabular}




\section{Logistic Regression Analysis}

To reveal the relative impact of variables on the facet and disc degeneration, logistic regression analysis was performed. The variables from the univariate analysis which were associated with the incidence of ASD were age, BMI, duration of instrument fixation, vertebral slip, and preoperative facet and disc degeneration change. Logistic regression analysis revealed that duration of instrument fixation of more than 15.5 months was a significant risk factor of the incidence of $L 4 / 5$ facet degeneration $(P=0.006$; odds ratio: $1.337,95 \% \mathrm{Cl}: 1.108-1.615)$. For the duration of fixation, a cut-off value of 15.5 months was determined to discriminate with the highest sensitivity a receiver operating characteristic curve (ROC)d specificity by receiver operating characteristic curve (ROC) analysis. The area under the curve (AUC) is 0.86 (95\% confidence interval 0.74-0.99). Duration of fixation more than 21.0 months was a significant risk factor of the incidence of $L 5 S 1$ facet degeneration ( $P=0.001$; odds ratio: $1.379,95 \% \mathrm{Cl}$ : $1.133-1.679)$. The AUC is 0.95 (95\% confidence interval 0.88-1.00) (Table 6 and Fig. 2).

Table 6

Mutivariate Logistic Regression for facet joint degeneration.

\begin{tabular}{|llll|}
\hline Level & Risk Factor & P value & OR(95\% Cl) \\
\hline L4/5 & Fixed time & 0.006 & $1.270(1.072-1.503)$ \\
\hline L5S1 & Fixed time & 0.001 & $1.379(1.133-1.679)$ \\
\hline
\end{tabular}

Evaluation of aggravation based on pre-operative grade suggested that patients with facet joint degeneration at L4/5 pre-operation had no significant difference for greater progression of degeneration compared to patients without preoperative facet joint degeneration. A similar relationship with preoperative grade was not found at L5/S1. The pre-operative grade of facet degeneration was not associated with post-operative progression of disc degeneration, and pre-operative disc degeneration had no relationship with post-operative progression of facet degeneration.

\section{Discussion}

A considerable number of patients, especially young patients, complain of lumbar pain or have bilateral lumbar spondylolysis during physical examination, without or only mild lumbar spondylolisthesis, and usually have no neurological problems in imaging, symptoms, and signs(15). However, there is no consensus or guideline for the treatment of this part of patients. The treatment of simple bilateral lumbar spondylolysis can be divided into conservative treatment and surgical treatment(16). The current clinically accepted view is that active surgical treatment should be adopted for patients who are ineffective in conservative treatment for 6 months and are in the terminal stage of isthmic fissure on imaging $(4,17)$.

Previous studies have revealed a great number and variety of surgical techniques for the spondylolysis repair, demonstrating the lack of consensus on a satisfactory procedure. It mainly includes inter-segmental fusion and intra-segmental isthmus repair(18). For patients with simple lumbar spondylolysis, fusion has a 
definite effect on the fixation of the vertebral body, effectively preventing the diseased vertebrae from further spondylolisthesis, however, it will sacrifice the mobility of the fused segment, and may accelerate the degeneration of the adjacent segments of the vertebral body and intervertebral disc; while the intrasegment repair is considered to preserve the anatomical structure(19). With the improvement of surgical technique and material development. The method of fixing the diseased segment by direct repair surgery gradually develops from the early isthmic lag screw(20), transverse process-spinous process wire(21), screw-hook construct(22) to the shaped rod and combination techniques. However, each of these approaches has its drawbacks. The isthmus is too small to choose a suitable lag screw, and the lack of bone grafting in the isthmus leads to difficulties in bone healing. The wiring technique requires greater surgical exposure, with extensive stripping of the muscle in order to expose the transverse process completely. The uneven force on the bilateral transverse processes can lead to complications such as transverse process fractures and wire loosening, which may lead to nonunion of the pars defect. Gillet et al. (23) firstly use "V" rods to connect bilateral pedicle screws instead of laminar hook fixation. Ulibarri et al. (24) used this improved method to implant bilateral pedicle universal screws to connect the bent "U"shaped titanium rod have achieved a satisfactory fusion rate(25). Although the hook-screw and shaped rod methods have achieved satisfactory results, a considerable number of spondylolysis patients are associated with laminosis or dysplasia of spinous processes, which may affect fixation strength.

In this study, the pars defect repair we propose using inter-segmental pedicle screws seems to be a technically simple and safe procedure that presents the advantage of placing the spondylolysis under strong compression to help ensure fusion. Unlike other techniques, which demands extensive muscle stripping, exposing the transverse process, injury of the interspinous ligament during the procedure. Easy surgical access through the Wiltse approach allows minimal soft tissue dissection and reduced blood loss. Since hyperextension and rotation are the main stresses in the fatigue fracture of the isthmus, these abovementioned various methods of inter-segment fixation have a weaker ability to resist rotation and extension, and the inter-segment fixation provides stronger stability. In addition, the connecting of two screws allows for progressive compression across the isthmus, which increase the degree of bony contact to promote higher fusion rate. Otherwise, for cases with spondylolisthesis within grade 1 and mild disc degeneration, motion segment fixation can correct and stabilize the spondylolisthesis. Compared with the method of inter-segment fixation, its disadvantage is that the original motion segment is fixed. Therefore, in order to restore the motion of this segment, the patients in our study have been removed the internal fixation after CT confirmed that the pars have completely union.

Facet joints and discs are both involved in stability of the lumbar spine construct $(26,27)$ and considered the relationships among facet joints and discs in adjacent segment degeneration $(28,29)$. To our knowledge, the incidence and risk factors of fixed and adjacent segment degeneration after inter-segment pedicle screw fixation for lumbar spondylolysis, have not been previously investigated. In this study, we identify the risk factors for facet joint and disc degeneration in order to predict and prevent this condition. After the follow-up on 54 patients, $100 \%$ bone healing were achieved. Only one patient had a reduction in disc height of $\geq 20 \%$ in the upper and fixed segments, respectively. When the internal fixation is removed,we found a $9 \%$ incidence of disc degeneration for 1 grade at the L4/5 and L5S1 levels, 
respectively (based on the Pfirrmann 5-grade classification system). However, no previous studies compare the development of adjacent and fixed disc degeneration in the patients treated with inter-segment pedicle screw fixation. Previous studies reported adjacent biomechanical alterations after lumbar fusion. Umehara et al.(30) reported that the load burden and weight shearing of the posterior column increased significantly at the adjacent segments. Weinhoffer et al.(31) also reported a significant increase in the disc pressure in the levels above the fused segments. In a systematic review, Harrop et al.(32) reported a $9 \%$ incidence of ASD after total disc replacement and a $34 \%$ incidence after fusion. We also found a $15 \%$ incidence of disc height decrease more than $10 \%$ at the L4/5 level and $17 \%$ incidence at the L5S1 level, however, the differences were not significant between pre- and post-surgery. The incidence of facet joint degeneration was $13 \%$ at the $L 4 / 5$ level and $17 \%$ at the L5S1level, respectively. Facet joint degeneration may arise from different mechanisms. Firstly, surgical factors such as damage to the articular process during screw placement may lead to an increased risk of facet joint degeneration. Increased loading of the adjacent level after fixation also increases the load on the surrounding facet joints $(33,34)$. Biomechanical studies have shown that the facet load can increase at the level of surgery after intervertebral fusion. Although there is no intervertebral fusion in this study, inter-segmental fixation may also increase the load on the facet joint.

This result of present study suggests that the duration of fixation as a risk factor associated with the occurrence of facet joint degeneration. In these patients, fixed time is considered as a significant factor for facet degeneration. The non-degeneration cut-off value of fixed time has been speculated to be within 15.5 months. As a matter of fact, patients in this series with successful pars union presented a mean value of fixed time of 17.04 months. Therefore, regular postoperative follow-up is required to determine the bony union of the pars defect. Once bony union is achieved, remove of the internal fixation should be recommended. In addition, bone morphogenetic protein-2 (BMP-2) can be used to achieve earlier and enhance fusion. The earlier the bony union occurs, the lower the incidence of facet joint degeneration. Secondary, our results have shown that older age and higher BMI are associated with the occurrence of facet joint degeneration at the L4/5 and L5S1 levels, respectively. In addition, Sagittal balance and spinopelvic parameters also probably influence facet joint degeneration development. Further study is needed to analyze spinopelvic parameters.

This study has some limitations. First, it was a retrospective study and was not performed as a comparative study. Second, the sample size in the present study was limited. It may increase the chances of making a type II error. Third, radiologic evaluations, including sagittal alignment assessment, were not performed.

\section{Conclusions}

In this study, inter-segmental pedicle screw fixation provides good surgical outcomes and good isthmic bony union rates in patients with lumbar spondylolysis. The duration of fixation was confirmed as a risk factor of facet joint degeneration. Once bony union is achieved, remove of the instruments should be recommended. 


\section{Abbreviations}

ASD adjacent segment degeneration; CT:computed tomography; MRI:magnetic resonance imaging; DH:disc height; DHI:disc height index; JOA:Japanese Orthpaedic Association; BMI:Body Mass Index; AUC:area under the curve; ROC:receiver operating characteristic curve; BMP-2:bone morphogenetic protein2.

\section{Declarations}

\section{Ethics approval and consent to participate}

The clinical retrospective study protocol was established, according to the ethical guidelines of the Helsinki Declaration and was approved by the Human Ethics Committee of the Seventh Medical Center of PLA General Hospital. Written informed consent was obtained from individual or guardian participants.

\section{Consent for publication}

The patients consented to the publication of their pictures as well as their anonymous and clustered data.

\section{Competing interests}

The authors declare that they have no competing interests.

\section{Funding}

The study was supported by the PLA Training Injury Prevention Project, China (no. 20XLS34) and the Capital Health Research and Development of Special Funding (no. 2020-2-5091). The funding bodies had no role in the design of the study or in collection, analysis, interpretation, or presentation of data.

\section{Authors' contributions}

HM was involved in conception and design, drafting the article, analysis and interpretation of data. YG was responsible for analysis and interpretation of data. PL was involved in study data collection and preliminary data analysis. GMZ, ZCZ, and TSS was involved in study conception, surgery, and patient's management. FL was involved in study conception, supervision, and administrative support. The authors read and approved the final manuscript.

\section{Acknowledgements}

We thank Xiumei Liu, Junfeng Wang and Simeng Zhang for their assistance with data acquisition. 


\section{References}

1. Fredrickson BE, Baker D, McHolick WJ, Yuan HA, Lubicky JP. The natural history of spondylolysis and spondylolisthesis. J Bone Joint Surg Am. 1984;66(5):699-707.

2. Beutler WJ, Fredrickson BE, Murtland A, Sweeney CA, Grant WD, Baker D. The natural history of spondylolysis and spondylolisthesis: 45-year follow-up evaluation. Spine (Phila Pa 1976). 2003;28(10):1027-35. discussion 35.

3. Standaert CJ, Herring SA. Spondylolysis: a critical review. Br J Sports Med. 2000;34(6):415-22.

4. Lim MR, Yoon SC, Green DW. Symptomatic spondylolysis: diagnosis and treatment. Curr Opin Pediatr. 2004;16(1):37-46.

5. Blanda J, Bethem D, Moats W, Lew M. Defects of pars interarticularis in athletes: a protocol for nonoperative treatment. J Spinal Disord. 1993;6(5):406-11.

6. Gillis CC, Eichholz K, Thoman WJ, Fessler RG. A minimally invasive approach to defects of the pars interarticularis: Restoring function in competitive athletes. Clin Neurol Neurosurg. 2015;139:29-34.

7. Radcliff KE, Kalantar SB, Reitman CA. Surgical management of spondylolysis and spondylolisthesis in athletes: indications and return to play. Curr Sports Med Rep. 2009;8(1):35-40.

8. Park P, Garton HJ, Gala VC, Hoff JT, McGillicuddy JE. Adjacent segment disease after lumbar or lumbosacral fusion: review of the literature. Spine (Phila Pa 1976). 2004;29(17):1938-44.

9. Cheh G, Bridwell KH, Lenke LG, Buchowski JM, Daubs MD, Kim Y, et al. Adjacent segment disease followinglumbar/thoracolumbar fusion with pedicle screw instrumentation: a minimum 5-year followup. Spine (Phila Pa 1976). 2007;32(20):2253-7.

10. Miyakoshi N, Abe E, Shimada Y, Hongo M, Chiba M, Sato K. Anterior decompression with single segmental spinal interbody fusion for lumbar burst fracture. Spine (Phila Pa 1976). 1999;24(1):67-73.

11. Quint DJ, Tuite GF, Stern JD, Doran SE, Papadopoulos SM, McGillicuddy JE, et al. Computer-assisted measurement of lumbar spine radiographs. Acad Radiol. 1997;4(11):742-52.

12. Inoue H, Ohmori K, Miyasaka K, Hosoe H. Radiographic evaluation of the lumbosacral disc height. Skeletal Radiol. 1999;28(11):638-43.

13. Pfirrmann CW, Metzdorf A, Zanetti M, Hodler J, Boos N. Magnetic resonance classification of lumbar intervertebral disc degeneration. Spine (Phila Pa 1976). 2001;26(17):1873-8.

14. Vanharanta H, Floyd T, Ohnmeiss DD, Hochschuler SH, Guyer RD. The relationship of facet tropism to degenerative disc disease. Spine (Phila Pa 1976). 1993;18(8):1000-5.

15. Gagnet P, Kern K, Andrews K, Elgafy H, Ebraheim N. Spondylolysis and spondylolisthesis: A review of the literature. J Orthop. 2018;15(2):404-7.

16. Kreiner DS, Baisden J, Mazanec DJ, Patel RD, Bess RS, Burton D, et al. Guideline summary review: an evidence-based clinical guideline for the diagnosis and treatment of adult isthmic spondylolisthesis. Spine J. 2016;16(12):1478-85.

17. Fujii K, Katoh S, Sairyo K, Ikata T, Yasui N. Union of defects in the pars interarticularis of the lumbar spine in children and adolescents. The radiological outcome after conservative treatment. J Bone 
Joint Surg Br. 2004;86(2):225-31.

18. Westacott DJ, Cooke SJ. Functional outcome following direct repair or intervertebral fusion for adolescent spondylolysis: a systematic review. J Pediatr Orthop B. 2012;21(6):596-601.

19. de Bodman C, Bergerault F, de Courtivron B, Bonnard C. Lumbo-sacral motion conserved after isthmic reconstruction: long-term results. J Child Orthop. 2014;8(1):97-103.

20. Buck JE. Direct repair of the defect in spondylolisthesis. Preliminary report. J Bone Joint Surg Br. $1970 ; 52(3): 432-7$.

21. Johnson GV, Thompson AG. The Scott wiring technique for direct repair of lumbar spondylolysis. J Bone Joint Surg Br. 1992;74(3):426-30.

22. Morscher E, Gerber B, Fasel J. Surgical treatment of spondylolisthesis by bone grafting and direct stabilization of spondylolysis by means of a hook screw. Arch Orthop Trauma Surg. 1984;103(3):1758.

23. Gillet P, Petit M. Direct repair of spondylolysis without spondylolisthesis, using a rod-screw construct and bone grafting of the pars defect. Spine (Phila Pa 1976). 1999;24(12):1252-6.

24. Ulibarri JA, Anderson PA, Escarcega T, Mann D, Noonan KJ. Biomechanical and clinical evaluation of a novel technique for surgical repair of spondylolysis in adolescents. Spine (Phila Pa 1976). 2006;31(18):2067-72.

25. Mohammed N, Patra DP, Narayan V, Savardekar AR, Dossani RH, Bollam P, et al. A comparison of the techniques of direct pars interarticularis repairs for spondylolysis and low-grade spondylolisthesis: a meta-analysis. Neurosurg Focus. 2018;44(1):E10.

26. Fujiwara A, Lim TH, An HS, Tanaka N, Jeon CH, Andersson GB, et al. The effect of disc degeneration and facet joint osteoarthritis on the segmental flexibility of the lumbar spine. Spine (Phila Pa 1976). 2000;25(23):3036-44.

27. Fujiwara A, Tamai K, An HS, Kurihashi T, Lim TH, Yoshida H, et al. The relationship between disc degeneration, facet joint osteoarthritis, and stability of the degenerative lumbar spine. J Spinal Disord. 2000;13(5):444-50.

28. Liang J, Dong Y, Zhao H. Risk factors for predicting symptomatic adjacent segment degeneration requiring surgery in patients after posterior lumbar fusion. J Orthop Surg Res. 2014;9:97.

29. Lee CS, Hwang CJ, Lee SW, Ahn YJ, Kim YT, Lee DH, et al. Risk factors for adjacent segment disease after lumbar fusion. Eur Spine J. 2009;18(11):1637-43.

30. Umehara S, Zindrick MR, Patwardhan AG, Havey RM, Vrbos LA, Knight GW, et al. The biomechanical effect of postoperative hypolordosis in instrumented lumbar fusion on instrumented and adjacent spinal segments. Spine (Phila Pa 1976). 2000;25(13):1617-24.

31. Weinhoffer SL, Guyer RD, Herbert M, Griffith SL. Intradiscal pressure measurements above an instrumented fusion. A cadaveric study. Spine (Phila Pa 1976). 1995;20(5):526-31.

32. Harrop JS, Youssef JA, Maltenfort M, Vorwald P, Jabbour P, Bono CM, et al. Lumbar adjacent segment degeneration and disease after arthrodesis and total disc arthroplasty. Spine (Phila Pa 1976). 2008;33(15):1701-7. 
33. Dunlop RB, Adams MA, Hutton WC. Disc space narrowing and the lumbar facet joints. J Bone Joint Surg Br. 1984;66(5):706-10.

34. Adams MA, Dolan P. Recent advances in lumbar spinal mechanics and their clinical significance. Clin Biomech (Bristol Avon). 1995;10(1):3-19.

\section{Figures}
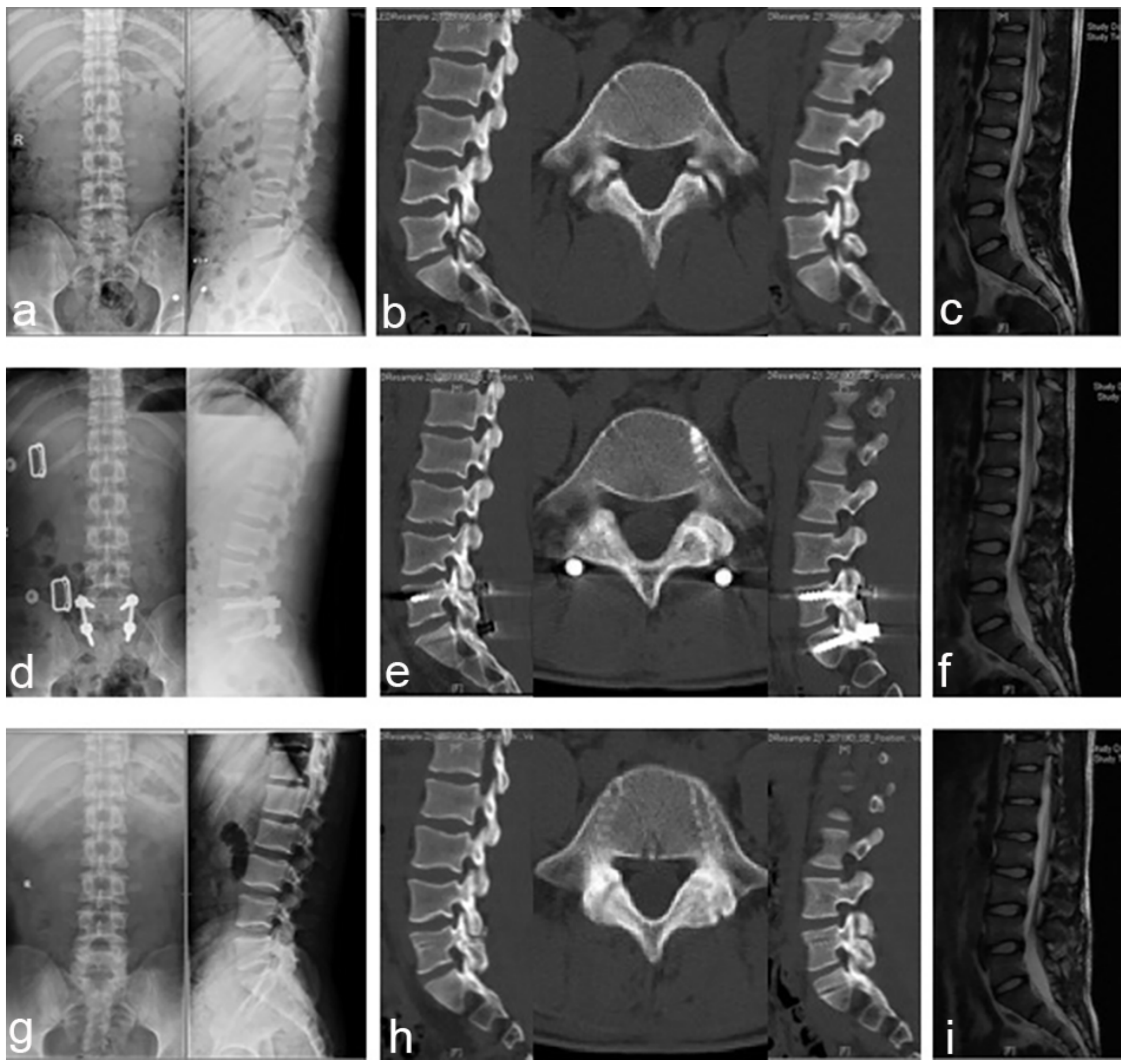

Figure 1 
Preoperative and postoperative images obtained in a 21-year-old man with L5 spondylolysis. a-c: Preoperative radiographs, CT scan and MRI. d: One-week post-operative radiographs. e: 12-months follow-up CT scan showed bilateral bony union of the pars defect. f: 15-months post-operative MRI. g: 15-months post-operative radiographs showed the lumbar instrumentations had been removed. $h$-i. 15 -months postoperative CT scan and MRI.
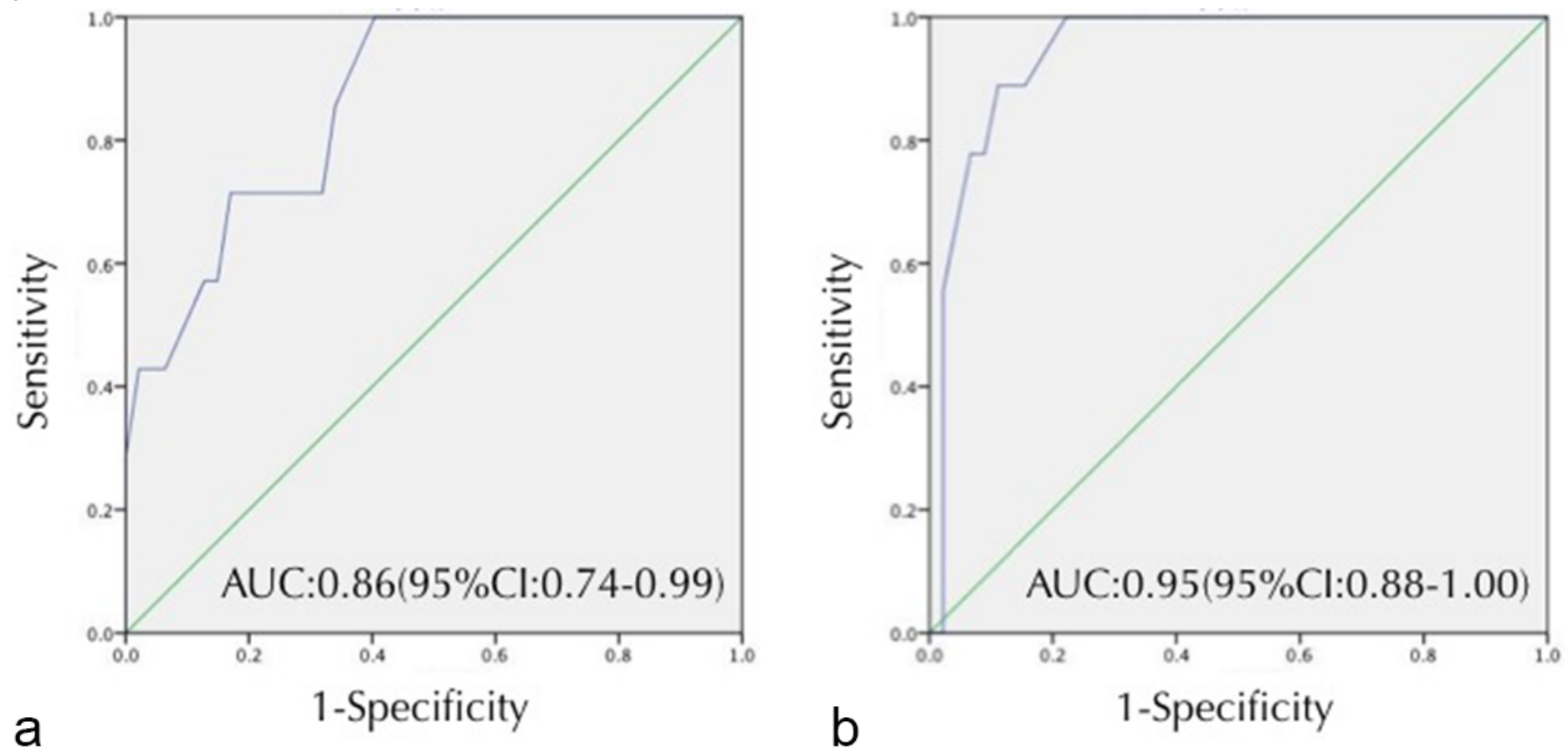

Figure 2

Logistic regression and ROC analysis. A: L4/5: a cut-off value of 15.5 months at which classification according to fixed time yields a sensitivity of $100 \%$ and specificity of $60 \%$. The area under the curve AUC is 0.80. B: L5S1: a cut-off value of 21.0 months at which classification according to fixed time yields a sensitivity of $89 \%$ and specificity of $89 \%$. The area under the curve AUC is 0.80 . 